\title{
Evaluation of Sensory Skills among Students with Visual Impairment
}

\author{
Suhib Saleem Saleem ${ }^{1, *} \&$ Mohammad Mousa Al-Salahat ${ }^{1}$ \\ ${ }^{1}$ College of Education, Najran University, K.S.A \\ *Correspondence: College of Education, Najran University, P.O.Box1988, Najran 61441, KSA. Tel: \\ 966-538-332-603. E-mail: suhib.saleem@yahoo.com
}

Received: April 23, 2016

Accepted: May 31, 2016 Online Published: June 13, 2016

doi:10.5430/wje.v6n3p66

URL: http://dx.doi.org/10.5430/wje.v6n3p66

\begin{abstract}
The purpose of the study was to evaluate the sensory skills among students with visual impairment(SVI). The sample contained of 30 students with blind and low vision enrolled in mainstreaming programs at general education schools at Najran in Kingdom of Saudi Arabia. A sensory skills scale was developed. The scale consisted of 20 items was distributed on four domains related to skills of touch, hearing, taste, and smell. The scale was applied on the sample of study by collaboration with teachers of SVI. The results showed that the degree of possessing sensory skills of visually impaired students was moderate. Moreover, there were significant differences in the skills of touch, taste and smell in favor of low vision students and in the skills of hearing in favor of blind students.
\end{abstract}

Keywords: blind; low vision; sensory skills

\section{Introduction}

The development of senses of the SVI is an urgent need. The senses of the SVI are significant in acquiring social adjustment skills (Kordestani, Daneshfar \& Roustaee,2014) to connect with the surrounding environment, help them gain experience and knowledge(Vermeij \& Geerat, 2006), receive understanding and respond to various stimuli, and the forming of concepts and meanings(Al-Louzi \& Mohammed, 2011). The developing of various skills for the SVI through sensory training is one of the most important methods, and it is done by stimulating different senses, such as the senses of hearing, touch, smell and taste. The blind children displayed a reliance on touch, smell and hearing for gaining information about the environment, In contrast, children with low vision depended on visual sense and other senses for their information (Aroraand \& Kour, 2012). The SVI needs to training on social and emotional skills (Kim, 2003) and technology skills (Elaine, 2003).

The sense of touch is one of the most important senses for the blind child (Hallahan, Kauffman \& Pullen, 2012). It is the major factor in the education of the blind in Braille, so training the hand in the touch sense, checking and closely getting experience is of great importance to its function as one of the main senses upon which the blind depend in his/her contact with the outside world, and in his/her life in general. The use of Braille contributes to improve the touch skills of students with visual impairment (Willagen \& Schellingerhout, 2004). On the other hand, the hearing sense is integrated with the sense of touch, where the sound of things is linked to the image formed by a blind child on touching this thing, which helps to entirely recognize the characteristics of this thing (Sulaiman, 2001). The ear also gives the blind information about what is happening in his/her surrounding environment, and thus can train the child to distinguish between near and far sounds in various directions, the high-pitch and low-pitch sounds, different tones of voice and the sounds of things in the environment.

The sense of smell also plays an important role in a blind person's life. The sense of smell is like the sense of hearing and touch. It enables the blind to realize things well and know the details of the environment from a distance or without direct contact (Tellevik \& Elmerskog, 2002). Moreover, the child's sense of taste has grows in the first weeks of birth, so it has the ability to distinguish between various foods, particularly the sweet, salty and sour taste, and respond to each of them with different expressions apparent on the face (Hawashin, 2002).

The child's early years are critical, and this fact applies to the visually impaired child the same extent as to the normal child, because in this period the child learns the skills and knowledge that represent the core of the process of academic learning. The SVI are in a dire need for such programs because of their active and principal role in making 
the SVI learn the skills and knowledge that help them adapt in an appropriate manner, and also these programs have a positive role in the family interaction with its child on one hand, and the interaction of the teacher and other children with him/her in future school environment on the other hand (Seleem, 2010).

Arora and Kour (2012) revealed that the SVI could recognize several items of sensory training tnventory through diverse senses like. The sense of touch is the most commonly used by SVI. Troster and Brambeng(1994) indicated that SVI prefer games that depend on the sense of hearing and touch. Christy, Shanimole and Nuthetie (2002) showed the importance of the sense of touch and smell. These senses enable SVI to distinguish between summer and winter clothes and clean and unclean clothes. Abdul Hadi (2001) focused on the development of sensory skills among SVI through training programs. In addition, Najdi (1990) confirmed the effectiveness of training programs in improving senses of SVI. On the other hand, some studies concluded that training the listening skills led to improved communication skills among SVI (Abu Zaiton \& Alewat, 2010; Edmands \& Pring, 2006; Katz, 2002; Tuncer \& Altunay, 2006).

In the Kingdom of Saudi Arabia, the programs of SVI are still inadequate to meet their needs, and there is a lack of studies conducted on the development of the sensory skills of the SVI in Saudi Arabia. The SVI need special care to help adapt to their environment through developing the sensory skills. Therefore, this study comes in order to pay attention to identify the extent of having the sensory skills, and then to provide those who are in charge of them with the skills that students need in order to develop these skills, and to draw the officials' attention to the development of the sensory skills they have, and the need to focus on them as one of the basic components of the way of life for SVI.

\section{Method}

\subsection{Participants}

The population of this study contained of $68 \mathrm{SVI}$ enrolled in mainstreaming programs at general education schools at Najran in the Kingdom of Saudi Arabia. Whereas, the sample consisted of 30 males and females students $(\mathrm{M}=15$, $\mathrm{F}=15$ ). The number of students with blind is (13), and the number of students with low vision is (17) students.

\subsection{Instrument}

To achieve the aims of the study, the sensory skills scale was developed, and it consisted of (26) items. In order to test the validity of the scale, the first version of the scale was reviewed by seven experts in the field of special education from the Department of Special Education at Najran University in Kingdom of Saudi Arabia. The final version contained of (20) items distributed to four domains related to skills of touch (5) items, hearing (5) items, taste (5) items, and smell five items. In addition, the reliability of each domain was as follows: touch skills ( $\mathrm{r}=0.81)$, hearing skills $(\mathrm{r}=0.79)$, taste skills $(\mathrm{r}=0.83)$, and smell skills $(\mathrm{r}=0.86)$. Thus, the Five Point Likert Scale was used.

\section{Results}

3.1 Results Related to the First Question: What is the level of sensory skills among SVI?. To answer this question means and standard deviations were used as shown in Table 1

Table 1. Means and Standard Deviations of Sensory Skills

\begin{tabular}{lcccc}
\hline Domain & N & M & SD & Level \\
\hline Touch Skills & 30 & 3.33 & 0.92 & Moderate \\
Taste Skills & 30 & 3.27 & 0.79 & Moderate \\
Hearing Skills & 30 & 2.87 & 1.01 & Moderate \\
Smell Skills & 30 & 2.37 & 1.19 & Moderate \\
\hline
\end{tabular}

Table 1 show that all the domains of the scale got a moderate level of sensory skills among SVI. Moreover, the domain of touch skills came in the first rank $(\mathrm{M}=3.33)$. Whereas, the domain of smell skills came in the last rank $(\mathrm{M}=2.37)$.

3.2 Results Related to the Second Question: Are there any statistically significant differences in level of sensory skills due to type of visual impairment? For this question, means, standard deviations and t-test were calculated as shown in table 2. 
Table 2. Means, Standard Deviations and T-Test According to Type of Visual Impairment

\begin{tabular}{lcccccc}
\hline Domains & Type & $\mathrm{N}$ & $\mathrm{M}$ & $\mathrm{SD}$ & $\mathrm{T}$ & $\mathrm{P}$ \\
\hline Touch Skills & Blindness & 13 & 2.92 & 0.76 & & $.03^{*}$ \\
& Low Vision & 17 & 3.65 & 0.93 & 2.28 & $.03^{*}$ \\
Hearing Skills & Blindness & 13 & 3.31 & 0.75 & & \\
& Low Vision & 17 & 2.53 & 1.07 & 2.23 & $.00^{*}$ \\
Taste Skills & Blindness & 13 & 2.85 & 0.90 & & \\
& Low Vision & 17 & 3.59 & 0.51 & 2.86 & $.01 *$ \\
Smell Skills & Blindness & 13 & 1.62 & 1.12 & & \\
& Low Vision & 17 & 2.94 & 0.90 & 3.59 & \\
\hline
\end{tabular}

$* \overline{\mathrm{P} \leq .05}$

Table 1 illustrates that there were statistically significant differences in level of sensory skills due to type of visual impairment. Thus, these statistical differences were in favor of students with low vision in the domains of touch skills, taste skills, and smell skills. While, there were statistically significant differences in the hearing skills in favor of blindness students.

\section{Discussion}

The results indicated that the sensory skills among SVI were moderate. The fact that the visually impaired students did not receive proper training for the development of the sensory skills can justify this result, as well as the lack of environmental stimuli surrounding the child or to lack of parents awareness. Moreover, development of sensory skills of SVI should be worked on through training programs. Scholars in the field of visual impairment in the Arab world noted that there is a weakness of the training programs and support services which aim to develop sensory skills of visually SVI. This requires from the experts in the visual impairment to reconsider of the programs and services provided for these students by conducting further studies on sensory skills(Zaiton \& Alewat, 2010). This results are consistent with several studies that indicated to the effectiveness of training programs in developing of sensory skills among SVI (Abdul Hadi, 2001; Najdi, 1990; Abu Zaiton \& Alewat, 2010; Troster \& Brambeng, 1994; Christy et al., 2002).

Results also showed there were differences between the means of SVI on the sensory skills scale according to the type of visual impairment. Furthermore, these differences in favor of low vision students in the skills of touch, taste and smell and in the skill of hearing in favor of blind students. Consequently, this may be due to that the blind depend on hearing in order to compensate of the weakness in the experience as a result of the loss of the sense of vision. The sense of hearing increases the of blind. It is necessary to focus on the environment rich in stimuli that helps the blind to use the sense of hearing. Abu Zaiton \& Alewat (2010) emphasized the importance of the development of listening skills for the blind by using the sensory training programs. Aroraand and Kour (2012) revealed the effectiveness of sensory training programs to improve the senses of touch, taste and hearing for SVI. In addition, Withagen, Vervloed, Janssen, Knoors and Verhoeven(2009) recommended to use the tactual profile in improving sensory skills in tactual of motor, sensory and perceptual for SVI.

\section{Conclusion}

Results of the study showed the importance of the senses of hearing, smell, touch and taste for SVI. Results also showed there were differences in the sensory skills these differences in favor of low vision students in the skills of touch, taste and smell and in the skill of hearing in favor of blind students. Based on these results the researchers recommended to conduct studies on developing sensory skills among SVI, to construct of educational programs for the development of these senses, and to involve parents of SVI in special training programs which aimed at developing these senses for their children. Future studies should search ways to improve the skills of touch, taste and smell among blind students.

\section{Acknowledgements}

This research project is funded by the Deanship of Scientific Research at Najran University in the Kingdom of Saudi Arabia under the grant number (NU/SHED/14/061). 


\section{References}

Abdul Hadi, D. (2001). Effectiveness of a training program for blind children in the light of their needs( unpublished master thesis), Ain Shams University, Cairo, Egypt.(in Arabic)

Abu Zaiton, J., \& Alewat, S. (2010). Effect of a training program in developing listening skills and academic self-concept among students with visual impairment. Damascus University Journal: Educational Sciences, 26(4), 215-250.(in Arabic)

Al-Louzi, S., \& Mohammed, S. (2011). Evaluation of sensory training services for children with visual impairment. Dirasat: Human \& Social Sciences, 38(2), 374-390.

Aroraand, S., \& Kour, R. (2012). Sensory training program for visually impaired children. International Journal of Scientific and Research Publications, 2(3), 1-3.

Christy, B., Shanimole, \& Nuthetie, R. (2002). Self-perceptions of visually impaired children aged 3-10 in India. Journal of Visual Impairment \& Blindness, 96(8), 596- 598.

Edmonds, C., \& Pring, L. (2006). Generating inferences from written and spoken language: A comparison of children with visual impairment and children with sight. British Journal of Developmental Psychology, 24, 337-351. http://dx.doi.org/10.1348/026151005X35994

Elaine, G. (2003). The benefits of and barriers to computer use for individuals who are visually impaired. Journal of Visual Impairment \& Blindness, 97(9), 536-551.

Hallahan, D., Kauffman, J., \& Pullen, P. (2012). Exceptional Learners: An introduction to special education. New Jersey: Person Education.

Hawashin, M., \& Hawashin, Z. (2002). Sensory education for kindergarten children. Amman, Jordan: Dar AlFikr. (in Arabic)

Katz, H. P. (2002). Treatment and evaluation indices of auditory processing disorders. Seminars in Hearing, 23(4), 357-364. http://dx.doi.org/10.1055/s-2002-35884

Kim, Y. (2003). The effects of assertiveness training on enhancing the social skills of adolescents with visual impairments. Journal of Visual Impairment \& Blindness, 97(5), 285-298.

Kordestani, F., Daneshfar, A., \& Roustaee, D. (2014). Comparison of quality of life and social skills between students with visual problems (blind and partially blind) and normal students. International Journal of Academic Research in Progressive Education and Development, 3, 384-391. http://dx.doi.org/10.6007/IJARPED/v3-i4/1376

Najdi, S. (1990). A proposed program for developing the senses of a disabled child in pre-school. Paper presented at the Fifth Conference of individuals with special needs, Cairo, Egypt. (in Arabic)

Sulaiman, A. (2001). The psychology of people with special needs. Cairo, Egypt: Al-Sharq Library. (in Arabic)

Tellevik, J., \& Elmerskog, B. (2002). Participation in ecologically valid activities: Mobility and rehabilitation in an African environment. Visual Impairment Research, 4, 161-174. http://dx.doi.org/10.1076/vimr.4.3.161.15901

Troster, H., \& Bambring, M. (1994). Play behavior and play materials in blind and sighted infants and preschoolers. Journal of Visual Impairment \& Blindness, 88(5), 421-433.

Tuncer, A., \& Altunay, B.(2006). The effect of a summarization-based cumulative retelling strategy on listening comprehension of college students with visual impairments. Journal of Visual Impairment \& Blindness, 100(6), 353-365.

Vermeij, G. (2006). Teaching exploration: Correcting a glaring flaw in the education of blind children. Future Reflections, 25(3), 1-2.

Willagen, J., \& Schellingerhout, R. (2004). Tactual Profile: An Assessment procedure for tactual functioning in children and adolescents: Validation of the instrument. In S. Ballesteros \& M. Heller (eds.), Touch, blindness and neuroscience, pp. 323-33. Madrid: Uned Press.

Withagen, A., Vervloed, M., Janssen, N., Knoors, H., \& Verhoeven, L. (2009). The tactual profile: Development of a procedure to assess the tactual functioning of children who are blind. British Journal of Visual Impairment, 27, 221-238. http://dx.doi.org/10.1177/0264619609106362 